\title{
A (in)capacitação digital no Brasil e os descaminhos dos cursos de Licenciatura
}

\author{
Tamara Benakouche
}

BENAKOUCHE, T. A (in)capacitação digital no Brasil e os descaminhos dos cursos de Licenciatura. In HAYASHI, MCPI., SOUSA, CM., and ROTHBERG, D., orgs. Apropriação social da ciência e da tecnologia: contribuições para uma agenda [online]. Campina Grande: EDUEPB, 2011. pp. 219-247. ISBN 978-85-7879-187-2. Available from SciELO Books <http://books.scielo.org>.

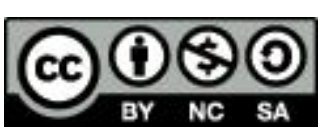

All the contents of this work, except where otherwise noted, is licensed under a Creative Commons Attribution-Non Commercial-ShareAlike 3.0 Unported.

Todo o conteúdo deste trabalho, exceto quando houver ressalva, é publicado sob a licença Creative Commons Atribuição Uso Não Comercial - Partilha nos Mesmos Termos 3.0 Não adaptada.

Todo el contenido de esta obra, excepto donde se indique lo contrario, está bajo licencia de la licencia Creative Commons Reconocimento-NoComercial-CompartirIgual 3.0 Unported. 


\section{A (in)capacitação digital no Brasil e os descaminhos dos cursos de Licenciatura ${ }^{1}$}

Tamara Benakouche

"O professor-emissor (informante) é um triste arcaísmo dentro de um contexto de informação saturada".(Lauro de Oliveira Lima, 1971)

Com a difusão das tecnologias de comunicação (TC), parece ampliar-se, no Brasil, o consenso em torno da ideia de que a inclusão digital é necessariamente uma condição para a inclusão social. Nesse sentido, observam-se mobilizações de variados segmentos da sociedade - que vão do setor público a ONGs, passando por várias iniciativas privadas - buscando facilitar o acesso de indivíduos de renda baixa às referidas tecnologias. No entanto, a tese que se pretende defender neste estudo é que a exclusão digital deve-se muito mais à crônica incapacidade do sistema de ensino

1 Parte deste trabalho foi apresentada no GT03 "Ciência, Tecnologia e Inovação Social" do XIII Congresso Brasileiro de Sociologia, ocorrido em Recife em maio/junho de 2007. 
nacional em cumprir seus objetivos de transmitir conhecimentos do que às dificuldades de acesso a computadores. Partindo dessa perspectiva, e com base em levantamento realizado por nós no Estado de Santa Catarina em 2007, o trabalho visará a analisar o funcionamento de cursos de Licenciatura, focalizando as atuais condições de formação de professores para o ensino fundamental e médio. Sabe-se que o desenvolvimento de uma tecnologia não termina necessariamente quando ela chega ao mercado; ela pode ser "re-inventada" através dos usos que lhe são dados. Tendo em vista que nem o computador, nem a internet foram inventados para servir à educação, pergunta-se: os educadores estão sendo capacitados a "reinventá-los"? Quais as expectativas dos educadores diante das TC? Será possível afirmar que a formação que vem sendo oferecida aos futuros profissionais do ensino lhes permitirá contribuir para promover a inclusão digital/social de seus futuros alunos?

O texto está organizado em quatro partes: a primeira consiste numa breve avaliação crítica das diretrizes que regem os cursos de Licenciatura no Brasil, tecendo-se ainda algumas considerações sobre o conceito de exclusão digital; a segunda discute a prioridade das políticas públicas existentes, voltada essencialmente para a capacitação digital de professores já em exercício (em especial, iniciativas e ações do ProInfo); a terceira examina alguns dados da pesquisa empírica realizada por nós, procurando mostrar a fragilidade da formação proporcionada pelos cursos em questão; e, finalmente, a quarta traz argumentos teóricos que podem ser utilizados para explicar a dificuldade dos educadores em se apropriar das TC. 


\section{Licenciaturas: uma trajetória de tentativas e erros}

Dizer que o ensino, no Brasil, vai mal não constitui nenhuma novidade. Ao longo dos últimos anos, a divulgação de dados oficiais, artigos de especialistas, matérias jornalísticas, dissertações e teses, dentre outros escritos, vêm repetindo isso à exaustão. Para corrigir os problemas - há que se reconhecer - medidas de várias ordens vêm também sendo tentadas, em diferentes governos, mas nenhuma parece atingir os objetivos visados. Esta observação, de caráter geral, é igualmente verdadeira no que diz respeito ao desempenho dos cursos de Licenciatura no país.

A preocupação com a formação de professores tem uma longa história no Brasil. De forma sistemática, costuma-se marcar seu início a partir da criação das primeiras escolas normais, entre 1835 e 1880 (PEREIRA, 2000). Com o passar do tempo, o ensino na área sofreu um sem número de reformas conceituais, curriculares, legais e administrativas, mas os esforços para torná-lo eficaz mostraram-se sempre vãos. Isso é verdadeiro desde a Reforma Benjamim Constant, na Primeira República - que nem chegou a ser implantada até as propostas presentes na atual Lei de Diretrizes e Bases (LDB), vigente a partir de $1996^{2}$.

Uma análise bastante esclarecedora sobre as razões dessa situação é feita por Libâneo; Pimenta (1999). Apesar de focalizarem a Licenciatura em Pedagogia, suas argumentações

2 Pereira (2000) traça um panorama sucinto dessas reformas, antes de analisar os dados de pesquisa empírica contemplando os cursos de Licenciatura da URFJ, da UERJ e da PUC-Rio e de oferecer uma série de subsídios para melhorá-los. Para reformas ocorridas em Santa Catarina, ver Fiori, 1991. 
podem ser aplicadas as outras áreas. Para esses autores, na origem dos problemas, estão as ambiguidades que desde a criação dos cursos de Pedagogia, em 1939, marcam tais cursos e os de Licenciatura.

Quando foi criado, o curso de pedagogia (...) se destinava a formar bacharéis (técnicos de educação) e licenciados em pedagogia, inaugurando o que veio a denominar-se esquema $3+1$, com blocos separados para o bacharelado e a licenciatura. Os professores dos antigos primário e pré-primário eram formados em Curso Normal nos institutos de educação, ao passo que os professores para os antigos cursos ginasial e colegial eram formados nas faculdades de Filosofia, Ciências e Letras (LIBÂNEO; PIMENTA, 1999).

A formação de professores em dois diferentes níveis de ensino - no médio e no superior - deu, assim, margem a várias insatisfações, que os autores analisam em detalhe. No entanto, o que queremos enfatizar aqui são os limites do próprio esquema $3+1$, que apesar de todas as críticas e tentativas de reforma, na prática persistem até hoje. O que ele significa?

Grosso modo, de acordo com tal sistema, nos cursos superiores com habilitação em Bacharelado e Licenciatura ${ }^{3}$, os alunos que optam pela Licenciatura devem, durante os

3 Em geral, os cursos de Matemática, Física, Química, Biologia, Letras, Geografia, História, Ciências Sociais, Psicologia, Filosofia, Educação Artística ou Artes e Pedagogia, ou seja, formações em áreas com disciplinas presentes nos antigos cursos ginasiais e colegiais, e atuais séries finais do ensino fundamental ( $5^{\mathrm{a}}$. à $\left.8^{\mathrm{a}}\right)$ e do ensino médio. 
três anos iniciais, cursar disciplinas de formação substantiva em suas especialidades (juntamente com aqueles que optaram pelo Bacharelado) e, só no último ano (o dito 3+1), cursar disciplinas de conteúdos didáticos e pedagógicos. $\mathrm{Na}$ verdade, algumas disciplinas com esses últimos conteúdos - como, por exemplo, Psicologia ou Filosofia da Educação - podem ou devem ser cursadas antes, mas o foco da formação - como a didática específica para o ensino da disciplina em que o aluno será licenciado (Didática em História, por exemplo) e a prática de ensino (o estágio em sala de aula) - concentra-se efetivamente no quarto ano $^{4}$.

Dentro dessa lógica, as disciplinas de conteúdo substantivo são oferecidas pelos departamentos ligados aos cursos dentro dos quais, a formação geral é buscada, enquanto as disciplinas de caráter didático-pedagógico são oferecidas pelos centros ou faculdades de educação. De maneira geral, grande parte dos professores desconhece os conteúdos desses dois blocos de disciplinas, o que em geral resulta num ensino precário, marcado pela fragmentação.

A LDB de 1996 procurou, em princípio, resolver alguns desses problemas (especialmente no Título VI, Dos Profissionais da Educação). Assim, em parte do seu artigo 62 , tenta corrigir a questão da formação de professores em dois níveis de ensino, ao determinar que "A formação de docentes para atuar na educação básica ${ }^{5}$ far-se-á em nível superior, em curso de Licenciatura, de graduação plena,

4 Observe-se, ainda, que na medida em que as disciplinas são comuns até um estágio bem adiantado, a opção do aluno por uma das habilitações não é feita necessariamente no início dos cursos, mas em algum momento do seu desenvolvimento.

5 Compreende educação infantil, ensino fundamental e ensino médio. 
em universidades e institutos superiores de educação (...)" [grifo nosso]. No entanto, curiosamente o mesmo artigo reproduz a situação anterior, ao continuar: (...) “[é] admitida, como formação mínima para o exercício do magistério na educação infantil e nas quatro primeiras séries do ensino fundamental, a oferecida em nível médio, na modalidade Normal" [idem].

Naturalmente isto mereceu críticas de vários especialistas, não só pela ambiguidade das disposições, mas também pela referência a um tipo aparentemente novo de instituição para formar docentes, no caso, os institutos superiores de educação. Segundo Bazzo (2004), a criação desses institutos era ideia recorrente na história das políticas públicas para o setor, a qual, por uma série de razões que analisa, nunca conseguira ser implantada; de acordo com a autora, ela teve um ressurgimento "solto e descontextualizado no interior do art. 62, parecendo mais um lapso da memória ou o fruto de alguma nostalgia de seu redator". Na verdade, por se situar fora das estruturas universitárias, os egressos desses institutos, hoje existentes principalmente em cidades do interior do país, não teriam uma formação satisfatória - por exemplo, não estariam capacitados para realizar pesquisas científicas - e, nesse sentido, sofreriam de um déficit de prestígio, tal como os dos cursos "apenas" profissionalizantes.

No que diz respeito ao pouco tempo dedicado às disciplinas didático-pedagógicas nas licenciaturas (apenas um ano), o artigo 65 da LDB estipula: "A formação docente, exceto para a educação superior ${ }^{6}$, incluirá prática de

6 Feita em nível de pós-graduação. 
ensino de, no mínimo, trezentas horas". A efetiva implantação de tal dispositivo - que aumenta consideravelmente a carga de aprendizagem específica - poderia implodir o esquema $3+1$, mas o que se observa é que isto não vem acontecendo de fato.

Os inúmeros decretos e outras figuras legais aprovadas desde a entrada em vigor da LDB, visando principalmente a regulamentar muitos dos seus artigos, constituem um emaranhado de difícil entendimento para os não-especialistas e isto é, sem dúvida, um dos fatores que explicam a lentidão para concretizar as mudanças. Além do mais, procurando adotar um espírito democrático, a LDB deu a vários dos seus dispositivos uma redação muito geral, deixando as especificidades para serem resolvidas pelo Conselho Nacional de Educação. Se por um lado, isso significou a possibilidade de participação da comunidade de especialistas e de interessados nas questões - uma demanda constante e legítima -, significou também a necessidade de buscar a construção de consensos (dificilmente alcançados), administrar críticas e protelar prazos, dentre outras dificuldades ${ }^{7}$.

De qualquer modo, como dito no início do presente item, problemas não são propriamente novidades na trajetória das licenciaturas brasileiras. O que nos inquieta, porém, é a percepção de que questões novas - e graves - estão se somando às antigas. Na nossa avaliação, elas emergem principalmente porque a grande maioria dos professores e

7 Um exemplo ao mesmo tempo de participação e de conflito foi a elaboração das diretrizes curriculares nacionais para formação de professores pelo Conselho Nacional de Educação, medida determinada pelo Decreto no. 3.276, de dezembro de 1999. 
responsáveis pelos cursos e instituições não reconhecem as potencialidades educacionais das tecnologias de comunicação. Nesse sentido, no Brasil, a escola é hoje o espaço por excelência da exclusão digital.

O uso da categoria exclusão para o estudo de questões sociais é de modo geral bastante controvertido. No entanto, apesar das críticas, a expressão "exclusão digital" continua sendo muito utilizada pelos que analisam as dificuldades da difusão das TC, provavelmente porque tem um apelo forte, que remete à noção de uma desigualdade extrema. $\mathrm{O}$ principal problema para o uso da categoria reside em seu caráter dicotômico, que obscurece a pluralidade de estados possíveis em relação ao acesso/não-acesso a determinados bens ou serviços. Com efeito, para além de uma polarização do tipo dentro ou fora, situações de déficit remetem mais apropriadamente a uma linha contínua, onde se pode estar num ponto mais ou menos próximo de suas extremidades positiva ou negativa. Ou seja, geralmente não se está incluído ou excluído de forma absoluta em face de alguma forma de consumo, mas mais ou menos incluído ou excluído em relação à capacidade de consumir de outros indivíduos. Nesse sentido, trata-se de uma situação essencialmente relacionals.

Com esses cuidados, entende-se que a expressão traduz um fenômeno com vários níveis de manifestação, mas que tem como ponto de partida o não-domínio das habilidades mais elementares para o uso de computadores e da internet. Trata-se, portanto, de um tipo de carência de formação, cuja

8 Argumento desenvolvido com mais detalhes em trabalho anterior (BENAKOUCHE, 2002). 
manifestação mais primária é o que vem sendo chamado de analfabetismo digital, isto é, desconhecimento "das noções básicas de informática indispensáveis para acesso à rede e seus serviços (...)" (TAKASHI, 2000, p.38).

No entanto, Bonilla (2001) discorda dessa visão minimalista, que se contenta com o aprendizado de noções básicas, pois, dentre outros aspectos, ela estaria impedindo uma política efetiva para a democratização do acesso aos equipamentos informatizados. Para a autora (op.cit.), "inclusão é um conceito mais abrangente do que isso, significa que aquele que está incluído é capaz de participar, questionar, produzir, decidir, transformar, é parte integrante da dinâmica social, em todas as suas instâncias." Habilidades tecnológicas básicas podem, segundo ela, ser adquiridas com certa facilidade, o que não acontece com a alfabetização em seu sentido mais amplo, ou seja, "em todas as áreas, abrangendo não só os processos de codificação, decodificação e compreensão, mas também processos de análise, organização, produção e socialização de informações e conhecimentos. E para isso, uma política de educação de qualidade é fundamental" (idem.).

Acreditamos, seguindo Bonilla, que uma inclusão digital efetiva exige mais do que uma mera capacidade para traçar perfis no Orkut ou para reenviar a listas de amigos mensagens em PowerPoint, de utilidade discutível. No entanto, há que se ter um ponto de partida, sem o qual se torna muito difícil extrair do uso dos computadores e da internet mais do que banalidades. E esse ponto de partida deveria ser objeto da educação formal de base. 


\section{Quando você for professor de alguma rede, poderá ser capacitado}

Paralelamente ao desenvolvimento das tecnologias digitais, floresceu no cenário internacional vasta produção bibliográfica procurando avaliar e, muitas vezes, também prever suas consequências ou "impactos". Assumindo com relação as mesmas quer visões positivas, quer visões negativas, em geral os autores acreditavam que uma profunda "revolução" social estava começando'. A qualidade dessa produção é muito variável e ao lado de obras de conteúdo muito futurista e genérico ${ }^{10}$, é possível encontrar análises mais comedidas e centradas em eventuais mudanças de alguns aspectos da vida social. Dentro deste segundo caso, encontram-se algumas obras focalizadas na educação, isto é, nos efeitos das TC sobre os processos de ensino e de aprendizagem ${ }^{11}$. Não cabe aqui analisar esses trabalhos ${ }^{12}$, mas chamar a atenção, por um lado, para o seu pioneirismo e sua rápida difusão e, por outro lado, um tanto contraditoriamente, para o equívoco de suas previsões quase sempre muito otimistas: com efeito, os processos de ensino e de

9 Para uma crítica à noção de impacto tecnológico e ao determinismo das análises positivas ou negativas em relação à técnica, ver Benakouche, 2005.

10 Talvez um bom exemplo seja o best-seller "A Terceira Onda", de Alvin Toffler, publicado em 1980.

11 Um dos autores mais difundidos, inclusive no Brasil, foi Pierre Lévy, especialmente seu trabalho "As Tecnologias da Inteligência", publicado originalmente em 1990.

12 No Brasil, também se desenvolveu uma pioneira produção acadêmica sobre a questão, mas de caráter menos prospectivo - à exceção, talvez, do trabalho de Lauro de Oliveira Lima, citado na epígrafe - e mais propositivo. Destaque pode ser dado para os trabalhos de José Armando Valente, da UNICAMP. 
aprendizagem pouco mudaram com o advento das TC. Ou mudaram para muito poucos.

No âmbito governamental, no Brasil, as discussões sobre as possibilidades de uso dos computadores na escola tiveram início já nos anos 1980. Assim, em 1981, o MEC organizou em Brasília o I Seminário Nacional de Informática na Educação, considerado um marco dentro das ações e das políticas públicas que se seguiram. E elas foram várias ${ }^{13}$. Assim, após a publicação das análises e recomendações desse I Seminário, ainda em 1981; da realização de um II Seminário, em 1982; e da criação de uma comissão interministerial para estudar a questão em 1983, foi elaborado e divulgado o Projeto EDUCOM (também em 1983), envolvendo a participação de mais de 20 entidades de ensino do país, tendo por objetivo produzir e disseminar uma produção científica sobre o que se passou a chamar então de "informática educativa". A partir daí, seguiram-se várias outras ações - acadêmicas, legais, etc $^{14}$. - que culminaram com a criação, em abril de 1997, do Programa Nacional de Informática na Educação (ProInfo), vigente ainda hoje, com o objetivo explícito de "promover o uso pedagógico da informática na rede pública de ensino fundamental e médio".

Estruturado de forma descentralizada, a coordenação do ProInfo cabe ao governo federal, enquanto sua operacionalização está a cargo dos Estados e Municípios. Para isto, foram criados em todo o território nacional os Núcleos de

13 Para um estudo das fases iniciais, ver Oliveira (1977).

14 Cronologia bastante completa pode ser consultada em http://www. proinfo.mec.gov.br. 
Tecnologia Educacional (NTE), onde cursos de capacitação passaram a ser realizados por "agentes multiplicadores", em princípio professores das redes estaduais de ensino previamente formados para tal fim, em cursos de especialização geralmente promovidos pelas Secretarias Estaduais de Educação. Através de convênios entre os vários níveis de governo, os NTE foram dotados de infraestrutura de informática (e, alguns, de comunicação), devendo os profissionais que nele trabalham auxiliar as escolas estaduais e municipais nas diferentes fases do processo de implantação das TC.

Não é o caso de fazer aqui uma avaliação do ProInfo, mas convém tecer algumas considerações a seu respeito. Sabe-se que em alguns estados ele funciona mais satisfatoriamente do que em outros, e que continuados esforços vêm sendo feitos para capacitar os professores do ensino fundamental e médio. No entanto, seus resultados nem sempre são os esperados. Salazar (2005) analisou a estruturação e o funcionamento de alguns cursos oferecidos via Secretaria Estadual de Educação, entre 2002 e 2004, a docentes de Santa Catarina e identificou vários dos seus entraves: falta de continuidade das políticas estaduais de capacitação (talvez o principal problema); falta de estrutura de acompanhamento aos professores, após a conclusão dos cursos; oferta de cursos nem sempre voltados às necessidades dos professores; critérios variáveis e nem sempre muito claros na escolha daqueles que fazem os cursos; cursos muitas vezes mal-estruturados, sob a responsabilidade de empresas pouco capacitadas; ausência de canais institucionalizados de participação dos profissionais dos NTE nas decisões das instâncias superiores são alguns deles. 
Partindo-se desse quadro - que sabemos ser ainda atual e que deve repetir-se nos demais estados do país - não fica difícil entender por que muitas das práticas educativas que têm sido objeto de capacitação ficam sem uso nas escolas.

De qualquer modo, diante das iniciativas e ações do ProInfo - sejam elas bem ou mal sucedidas - uma questão se impõe: por que a formação de futuros professores, objetivo das licenciaturas, não tem merecido a mesma atenção dos governos? É sem dúvida fundamental capacitar para o uso das TC os professores em exercício, formados há 25, há 15 ou há cinco anos; mas, por que as universidades não promovem o mesmo tipo de capacitação para os milhares de licenciados que se formam todos os semestres, nas várias disciplinas?

\section{Tecnologias? Que tecnologias?}

Segundo dados do Centro de Estudos sobre as Tecnologias da Informação e da Comunicação/CETIC, ligado ao Comitê Gestor da Internet no Brasil (CGI.br) - órgão criado pelo governo brasileiro, em 1995, para coordenar todas as iniciativas ligadas aos serviços da rede - entre setembro/novembro de 2008 , no país, $47 \%$ de indivíduos já haviam acessado a internet pelo menos uma vez na vida, dos quais $53 \%$ o faziam diariamente ${ }^{15}$.

Tais índices de apropriação social da mais importante das TC - índices que se elevam constantemente e que atestam sua crescente popularização no país - parecem ser

15 Fonte: http://www.cetic.br, consultado em 04/01/2010. 
ignorados pelos cursos de licenciatura. De maneira geral, as novas mídias não são usadas pelos professores em suas práticas docentes; o estudo de suas potencialidades educativas é raro ou inexistente; e seu ensino, quando existe - em disciplinas genéricas, como "Informática e Educação" ou assemelhadas - destina-se muito mais a instrumentalizar os alunos no "pacote Microsoft" (especialmente no Word e no Power Point) do que promover o conhecimento de softwares educativos ou desenvolver estratégias para seu uso.

Levantamento realizado por nós em Santa Catarina, entre novembro de 2006 e março de 2007, junto a 16 instituições vinculadas à Associação Catarinense das Fundações Educacionais (Sistema ACAFE), confirma esse quadro ${ }^{16}$. Dados obtidos através de consultas às suas home-pages revelam que essas instituições ofereciam 87 cursos de licenciatura, o que dava uma média de 5,4 cursos por instituição ${ }^{17}$. O maior número de cursos, no caso 11, estava na FURB, de Blumenau, que, curiosamente, mantinha uma Licenciatura em Computação e outra em Ciências da Religião.

Disciplinas que de alguma maneira fizessem referência ao ensino das TC foram buscadas nas grades curriculares

16 Apesar do foco em Santa Catarina, acreditamos que os resultados da análise podem ser estendidos a outros do Brasil. Observe-se que a mesma pesquisa - que recebeu apoio do $\mathrm{CNPq}$ - também incluiu a Universidade Federal (UFSC), mas, nesse caso, a abordagem foi de ordem qualitativa, com entrevistas a professores e alunos dos cursos de Licenciatura em Geografia e em Matemática.

17 Alguns desses cursos, como os de Pedagogia, eram oferecidos em mais de um campus (isto é, mais de um município); no entanto, sendo da mesma instituição, foram computados como um único curso. No caso dos cursos de Letras, aqueles que ofereciam duas ou mais habilitações (Inglês e Espanhol, por exemplo) também foram computados como sendo apenas um curso. 
doscursos, e, quando disponíveis, nas listagens das ementas. No caso, foram usadas palavras-chave como: tecnologia ou tecnologias, informática, informação, comunicação, mídia, computador e internet. Naturalmente, nada garantia que os títulos das disciplinas e/ou as ementas expressassem de fato os conteúdos estudados, mas sua simples presença já indicaria que a instituição estava atenta à questão. Assim, foram encontradas disciplinas com tais características em 36 cursos, o que representa $41,4 \%$ do total. Considerando a discussão conduzida até aqui, esse valor pode parecer elevado, mas cumpre esclarecer que quase todos os cursos registravam apenas uma disciplina do tipo, com títulos genéricos, como os exemplificados na Tabela 1. Dentre as licenciaturas que não tinham nenhum registro de formação para o uso das TC, quatro eram em Pedagogia.

Tabela 1 - Oferta de disciplinas com alguma referência às TC Sistema ACAFE - Santa Catarina - Fevereiro de 2007

\begin{tabular}{|l|c|c|l|}
\hline \multicolumn{1}{|c|}{ Instituição* } & $\begin{array}{c}\text { No. de } \\
\text { cursos de } \\
\text { licenciatura }\end{array}$ & $\begin{array}{c}\text { No. de cursos com } \\
\text { disciplinas com } \\
\text { alguma referência } \\
\text { às TC }\end{array}$ & \multicolumn{1}{|c|}{$\begin{array}{c}\text { Título da disciplina } \\
\text { "padrão" }\end{array}$} \\
\hline 1. UDESC & 3 & 3 & Títulos variados \\
\hline 2. FURB & 11 & 6 & $\begin{array}{l}\text { Educação e } \\
\text { Tecnologias }\end{array}$ \\
\hline 3. UNIVALI & 7 & 4 & $\begin{array}{l}\text { Educação, Comunica- } \\
\text { ção e Tecnologias }\end{array}$ \\
\hline 4. UNISUL & 8 & 5 & $\begin{array}{l}\text { Informática Aplicada à } \\
\text { Educação }\end{array}$ \\
\hline 5. UNOESC & 5 & 3 & $\begin{array}{l}\text { Informática na } \\
\text { Educação }\end{array}$ \\
\hline 6. UnC & 9 & 1 & Títulos variados \\
\hline 7. UNIPLAC & 6 & Sem informações & Títulos variados \\
\hline 8. UNIDAVI & 4 & 1 & Títulos variados \\
\hline 9. UNESC & 8 & 1 & \\
\hline
\end{tabular}




\begin{tabular}{|c|c|c|c|}
\hline Instituiçãõ ${ }^{*}$ & $\begin{array}{c}\text { No. de } \\
\text { cursos de } \\
\text { licenciatura }\end{array}$ & $\begin{array}{l}\text { No. de cursos com } \\
\text { disciplinas com } \\
\text { alguma referência } \\
\text { às TC }\end{array}$ & $\begin{array}{l}\text { Título da disciplina } \\
\text { "padrão" }\end{array}$ \\
\hline 10. UNIFEBE & 3 & 2 & Títulos variados \\
\hline 11. UNERJ & 1 & 1 & Não cabe. \\
\hline $\begin{array}{l}\text { 12. UNOCHA- } \\
\text { PECÓ }\end{array}$ & 9 & 6 & $\begin{array}{l}\text { Tecnologias da } \\
\text { Educação }\end{array}$ \\
\hline 13. UNIVILLE & 8 & 2 & Títulos variados \\
\hline 14. UNIBAVE & 3 & 0 & - \\
\hline 15. FEHH & 1 & 1 & Não cabe \\
\hline 16. USJ & 1 & 0 & - \\
\hline TOTAL & 87 & 36 & - \\
\hline$\%$ & 100,0 & 41,4 & \\
\hline
\end{tabular}

Fonte: Tabela elaborada por nós, a partir de levantamento nos sites das instituições.

* UDESC (Univ. do Estado de SC); FURB (Fundação Regional de Blumenau); UNIVALI (Univ. do Vale do Itajaí); UNISUL (Univ. do Sul de SC); UNOESC (Univ. do Oeste de SC); UnC (Univ. do Contestado); UNIPLAC (Univ. do Planalto Catarinense); UNIDAVI (Univ. para o Desenvolvimento do Alto Vale do Itajaí); UNESC (Univ. do Extremo Sul Catarinense); UNIFEBE (Centro Universitário de Brusque); UNERJ (Centro Universitário de Jaraguá do Sul); UNOCHAPECÓ (Univ. Comunitária Regional de Chapecó); UNIVILLE (Univ. da Região de Joinville); UNIBAVE (Centro Universitário Barriga Verde); FEHH (Fundação Educacional Hansa Hammonia); USJ (Centro Universitário Municipal de São José).

No entanto, os alunos das licenciaturas, como a grande maioria dos jovens universitários, sabem usar e usam o computador e a internet no seu dia a dia. Em trabalho realizado porNascimento (2006) com alunos da disciplina Metodologia de Ensino do curso de Licenciatura em Geografia da Universidade Federal de Santa Catarina (UFSC), a autora constatou que $74 \%$ deles acessavam a internet todos os dias, 
e $21 \%$ de duas a três vezes por semana. Dentre os principais motivos para esses acessos, destacaram-se ler/enviar e-mails e, o que parece muito curioso (e positivo), pesquisar material para trabalhos acadêmicos (ambas as alternativas aparecem com registro de $32 \%$ ). Perguntados como haviam adquirido conhecimentos sobre o uso das TC, as respostas não deixam nenhuma dúvida sobre a omissão da instituição universitária no processo: $16 \%$ declararam dever sua aprendizagem a cursos privados, $21 \%$ a amigos e parentes, enquanto $63 \%$ o fizeram sozinhos, "fuçando", ou seja, explorando de forma autônoma as possibilidades dos artefatos, na base do ensaio-e-erro ${ }^{18}$. A alternativa "curso na UFSC", presente no instrumento de coleta de informações, não recebeu nenhum registro.

Na mesma pesquisa, buscando explicar tal situação, um professor entrevistado expressou um tipo de condenação às políticas de capacitação digital que já foi muito comum no passado, mas que julgávamos esquecido: “É muito bonito o discurso 'ah, a inclusão digital, blá, blá, blá, blá (...); essa chamada 'inclusão digital" é mais uma balela, é mais discurso para vender computador" (NASCIMENTO, 2006, p.25). E completa, não sem razão dessa vez, expressando de forma resumida e direta a falência do ensino como um todo no país: "Eu acho que a dificuldade maior é saber ler e escrever" (op.cit., p.26).

18 Esses percentuais se assemelham aos encontrados por Oliveira (2005), em pesquisa feita junto a um curso de pós-graduação em Educação, ou seja, o fenômeno parece ser verdadeiro para todos os níveis de ensino. Segundo o autor, 74\% dos informantes afirmaram ter aprendido a usar recursos computacionais - inclusive a Internet - sem qualquer ajuda, e $88 \%$ através de consultas a amigos e/ou especialistas. (op. cit.). 
Não se pode dizer que o Governo Federal não está ciente das insuficiências dos cursos de licenciatura no país. Assim, continua buscando desenvolver políticas para tentar enfrentá-las, como, por exemplo, o Programa de Consolidação das Licenciaturas - PRODOCÊNCIA, lançado em 2006, através da Secretaria de Educação Superior do Ministério da Educação (SESU/MEC). Seu objetivo principal é justamente "ampliar a qualidade das ações voltadas à formação de professores, priorizando a formação inicial desenvolvida nos cursos de licenciaturas das Instituições Federais de Ensino Superior (IFES)" ${ }^{19}$ Quando da sua criação, abriu um edital para financiar propostas de ações a serem enviadas por essas Instituições, destinando valores entre $R \$ 80.000,00$ e $R \$ 30$ 000,00 para cada uma delas. Um total de 28 IFES foi então contemplado. Dentre os temas dos projetos aprovados, foi significativo verificar que o maior interesse voltou-se para a estruturação dos currículos dos cursos (demanda de $25 \%$ das IFES). O que, no entanto, apresentou-se como uma informação inovadora (e animadora) foi o elevado percentual (18\%) de projetos tendo como temática "a utilização de novas tecnologias nos cursos de licenciaturas" ${ }^{20}$. Mesmo se estes $18 \%$ significavam apenas cinco IFES - e se nem todos os projetos destinavam-se ao uso didático-pedagógico do computador/internet - isto já pode ser considerado um avanço.

19 Fonte: http://portal.mec.gov.br. Está ocorrendo também grande apoio à criação de Licenciaturas na modalidade de Ensino a Distância, através de ações da Secretaria de Educação a Distância (SEED) do MEC. Acreditamos que algumas dessas ações são bastante promissoras, mas por enquanto elas não são objeto de nossa investigação.

20 Fonte: http://portal.mec.gov.br/sesu. Consultado em 6/12/06. 
Com efeito, de maneira geral, exceto iniciativas isoladas de alguns professores mais motivados, nas instituições de ensino superior predomina uma completa falta de interesse pela questão. Fecham-se os olhos para as mudanças sociotécnicas em curso, para a construção de uma sociedade onde o uso das TC está cada dia mais presente. É como se o acesso dos adolescentes - de todas as classes sociais, observe-se - a jogos, sites de relacionamentos e blogs, dentre outras possibilidades oferecidas pela internet, não estivesse acontecendo, e num ritmo cada vez mais acelerado.

Naturalmente não existe uma única razão para o quadro descrito aqui, mas um somatório delas. Há, entretanto, um ponto de elevada concordância entre os especialistas e vivido na prática por qualquer professor universitário: as universidades não estão interessadas nas licenciaturas, preferindo privilegiar os cursos de pós-graduação e as atividades de pesquisa. Citando trabalho coordenado por Vera Maria Candau, ainda em $1988^{21}$, Mendonça (2002, p.18) informa: "Os resultados da pesquisa permitiram levantar a hipótese de que quanto maior é o envolvimento da universidade com pesquisa e pós-graduação, mais nítida é a hierarquia de prestígio das atividades acadêmicas - na qual a docência ocupa o escalão mais baixo - e menor o interesse institucional por cursos de licenciatura." E, de modo contundente, pergunta-se (idem): “Como valorizar a formação de professores em um país onde a vontade política não se compromete, de fato, com questões básicas de educação e onde o magistério - dadas as péssimas condições de

21 "Novos rumos da Licenciatura". Relatório final de pesquisa. Rio de Janeiro: Departamento de Educação, PUC, 1998. 
trabalho e remuneração - se transformou em atividade de caráter marginal ou provisório, em contingência mais do que opção?"

Libâneo; Pimenta (1999) também fazem críticas à política de formação, mas, no caso, àquela defendida pelo movimento de educadores, que teria gerado uma visão "militante" dos profissionais da educação, numa abordagem que chamam de "sociologizada": "De acordo com essa abordagem, bastaria ao professor ter uma visão política, globalizante, das relações entre educação e sociedade, compromisso político etc., que o resto viria por acréscimo. (...) Foi um grande equívoco dissolver o específico da prática educativa nas salas de aula (a aprendizagem, o crescimento cognitivo dos alunos etc.) na prática política. Faltou entender que um trabalho bem feito com as crianças no interior das salas de aula também é um ato político, e dos mais nobres".

Além desses aspectos, podemos ainda fazer referência ao fato de estarmos tratando de uma inovação tecnológica que, como tal, é sujeita a uma lógica de difusão não intrínseca aos aparatos envolvidos, mas que está relacionada às expectativas dos diferentes atores sociais com relação a eles. Assim, podemos retomar as questões feitas na introdução deste estudo: quais as expectativas dos educadores diante das TC? Como poderão "reinventá-las" com usos tão pouco criativos como os que lhes são ensinados nos cursos de Licenciatura? 


\section{A crença (equivocada) na oposição tecnologia versus humanização}

O que a nossa pesquisa com certeza deixou claro foi que os cursos de licenciatura no país continuam a se organizar e a funcionar como se as TC não existissem. Por que isso acontece? Quais os argumentos que lhes são desfavoráveis?

Já esboçamos aqui algumas respostas, mas acreditamos que na origem de muitas das restrições feitas a essas tecnologias encontra-se, sobretudo, a crença de que seu uso acarretaria na perda da humanidade própria da relação educador-educando. Tal suposição - que pode ser percebida em diferentes nuanças nas falas de alguns professores entrevistados e está presente em textos de vários educadores - revela um entendimento equivocado a respeito da natureza da técnica, considerada, no caso, como algo oposto ao humano. Isso demonstra, antes de mais nada, desconhecimento da história das invenções e da história das civilizações.

Ora, por um lado, sabe-se que todas as inovações técnicas resultam de ações humanas. Elas não caem do céu, nem surgem de um processo de geração espontânea, mas são construídas no jogo das relações sociais. Por outro lado, não existiriam civilizações sem o desenvolvimento de técnicas. O filósofo Milton Vargas (1994, p.171) sintetiza todos os limites da tese da "desumanização" da técnica ao afirmar, com muita propriedade: "Não tem sentido imaginar o homem antes de ele próprio fazer sua linguagem e sua técnica. Dizer que o homem 'inventou' a linguagem e a técnica é, assim, petição de princípio; pois, teria sido por meio desses 'inventos' que algo que não era humano tornou-se 
homem". Na mesma linha de pensamento, outro filósofo - o conservador Gustavo Corção! -, já em 1952, ponderava (CORÇÃO, 1952, p.11-12): “Dizer que a técnica e a ciência desumanizam o homem equivale a afirmar que o homem é mais plenamente humano na selva do que na universidade ou na fábrica, e isto é uma tese do naturismo que o bom senso e a sã filosofia rejeitam".

Por trás dessa crença, na oposição humano versus técnica, encontra-se mais uma vez a influência do determinismo tecnológico, ou seja, a suposição equivocada de que as tecnologias têm autonomia, vida própria, são independentes da ação dos indivíduos e, portanto, podem ser boas ou más em si mesmas. Esquece-se de que elas são construídas dentro de uma lógica que é essencialmente social.

No entanto, insistir apenas no papel da sociedade na definição das trajetórias das técnicas leva ao risco de se cair em outro determinismo, no caso, o determinismo social. Ainda mais quando se usa o termo "sociedade" sem levar em conta as ambiguidades que ele tradu ${ }^{22}$. Na verdade, como demonstram pesquisas em Estudos da Ciência e da Técnica ou Análise Sociotécnica, nem a "sociedade", nem qualquer grupo social, por mais poderoso que seja, são capazes de criar tecnologias sozinhos ou de impor seu uso ao conjunto de indivíduos ${ }^{23}$.

22 Para uma discussão sobre esse ponto, a leitura da Introdução do livro As Consequências da Modernidade, de Anthony Giddens (1991), pode ser muito útil, especialmente para os não especialistas.

23 Análise das várias correntes que compõem essa linha de investigação é feita em Benakouche (2005). O que segue é um resumo dos seus principais argumentos. 
O historiador Thomas Hughes (1983) - um dos mais importantes representantes da Análise Sociotécnica - num trabalho já clássico sobre a difusão da eletricidade nos Estados Unidos, na Inglaterra e na Alemanha, deixou muito claro que ela não se deu apenas pela invenção de dínamos e transformadores, mas graças à existência de uma multiplicidade de atores envolvidos no processo inovador. Assim é que considera aspectos tão díspares quanto interesses empresariais e governamentais, estilos nacionais ou culturais de gestão, personalidade dos inventores, caráter das legislações sobre o controle dos serviços públicos e sobre patentes, respostas dos usuários, além do desenvolvimento dos artefatos físicos, demonstrando que cada um deles interferiu nos demais. Para dar conta dessas relações, cunhou o conceito de "sistema técnico amplo" 24 , que vem sendo usado desde então por pesquisadores de diferentes países.

Na relação tecnologia versus sociedade, o processo chave, na verdade, chama-se negociação. Esse é um dos pontos centrais na argumentação de Bruno Latour, outro importante representante dessa linha de análise, que em seus trabalhos sempre insiste na necessidade de se "abrir a caixa-preta da técnica" para se poder conhecer os interesses envolvidos em sua construção, bem como as negociações realizadas durante sua trajetória. Isso fica bem ilustrado num detalhado estudo sobre a construção de um veículo elétrico na França - que não chegou a ser viabilizado onde demonstra que as relações entre os atores envolvidos são constantemente traduzidas em função dos interesses

24 Tradução da expressão Large Technical System, também conhecida pela sigla LTS. 
de cada um, e que são essas traduções (ou seja, interpretações) os objetos das negociações (LATOUR, 1996). Isso leva à formação de uma rede em que as associações se fazem de maneira mais ou menos sólida, rede que envolve tanto atores humanos como não-humanos (os artefatos e processos técnicos). "Não há tecnologia sem regras, sem assinaturas, sem burocracia e sem selos", lembra o autor (op. cit., p.45).

A história social da técnica está repleta de exemplos de patentes que não conseguiram apoio de financiadores, de inovações que foram ignoradas pelo público ou que tiveram aceitação momentânea para logo depois cair em desuso; de artefatos usados apenas por determinados segmentos sociais, e assim por diante. Isso é o que mostra ainda o sociólogo holandês Wiebe Bijker, ao estudar a trajetória de inovações como a bicicleta, a baquelita (resina sintética, precursora do plástico) e a lâmpada fluorescente (BIJKER, 1995). Com o auxílio de uma série de conceitos originais, ele mostra o caráter relacional - e, portanto, contingente - dos processos, os quais estão longe de apresentar a linearidade implícita no modelo clássico, segundo o qual uma inovação se faz por etapas sequenciais. Como Latour, ele também integra o conceito de rede em seu quadro explicativo. Este é útil, por exemplo, para argumentar por que muitas vezes os usos dados a um artefato diferem das intenções iniciais dos seus inventores. Bom exemplo disso é justamente o uso das TC na educação, já que não foram inventadas para tal fim.

Convém salientar que as considerações aqui apresentadas não pretendem afirmar que a tecnologia é neutra; o que se defende é o seu caráter socialmente construído, ou seja, negociado: se nós estamos nas mãos da tecnologia, 
ela também está em nossas mãos, como insiste Latour. O problema dessa fórmula não reside, porém, no termo tecnologia, mas no termo nós. Entendê-lo exige algum conhecimento sociológico, é preciso que isso seja dito. Responder à questão "nós, quem?" supõe uma reflexão teórica mais complicada do que parece, pois remete a várias tradições da Sociologia. Negociar significa fazer política, travar uma relação de força entre interesses conflitantes, e longe de ser uma prática extraordinária ou de conteúdo negativo, exprime a realidade cotidiana da vida social nas sociedades democráticas modernas.

\section{Considerações Finais}

Não é porque determinada tecnologia existe e chega ao mercado, que ela necessariamente se torna objeto de consumo da "sociedade"; ela deve "convencer" os consumidores, tarefa sem dúvida facilitada quando há uma demanda-explícita ou potencial-para a inovação em questão, ou um contexto social favorável. O que nossa pesquisa pretendeu mostrado é que os consumidores representados por professores e gestores de cursos de licenciatura não estão convencidos da necessidade ou da importância de introduzir nesses cursos o ensino prático - que não exclui o exercício de uma postura crítica, tão cara aos pedagogos - das várias possibilidades de uso das TC na educação. No entanto, o contexto social mostra-se cada vez mais favorável à adoção desse tipo mudança. Não há como negar que os alunos dos cursos fundamentais e médios - onde deverão atuar os licenciados - usam computadores com maior ou menor regularidade e, em geral, gostam muito de fazê-lo. 
Mesmo aqueles economicamente menos favorecidos também o fazem, já que até nos rincões mais periféricos do país é possível encontrar uma lan house. É certo que o uso das TC na educação tanto pode levar a práticas positivas quanto a práticas negativas (como a do sempre lembrado plágio). No entanto, tudo depende de como elas serão traduzidas e negociadas pelos atores sociais envolvidos na sua "reinvenção". Acreditamos, porém, que só rompendo com o senso comum será possível "reinventar" computadores e uma internet a serviço da educação, reinventando ao mesmo tempo cursos de licenciatura de qualidade, democráticos e à altura dos desafios colocados pela sociedade brasileira tal como se apresenta hoje. Recusar esse desafio significará a eterna reprodução do "professor-emissor" que o grande educador Lauro de Oliveira Lima condenava, já em 1971, como citado na epígrafe deste estudo.

\section{Referências}

BAZZO, V. L. Os institutos superiores de educação ontem e hoje. In: Educar, n.23, 2004. Curitiba, Editora UFPR, p.267-283.

BENAKOUCHE, T. A Escola enquanto Espaço de Reprodução da Exclusão Digital. In: Estudos de Sociologia, v.8, n.1/2, jan./dez. 2002. Recife, PPGS/UFPE, p.51-68.

BENAKOUCHE, T. Tecnologia é sociedade: contra a noção de impacto tecnológico, In: DIAS, L. C.; SILVEIRA, R. L. L. 
de (orgs.). Redes, sociedades e territórios. Santa Cruz do Sul: EDUNISC, 2005. p.79-106.

BIJKER, W. Of Bicycles, Bakelites, and Bulbs. Toward a Theory of Sociotechnical Change. Cambridge, Mass., The MIT Press, 1995.

BONILLA, M. H. O Brasil e a alfabetização digital. Jornal da Ciência, Rio de Janeiro, 13 de abril de 2001. Disponível em: <http://www.faced.ufba.br/ bonilla/artigojc.htm>. Acesso em 26/03/07.

CORÇÃO, G. As Fronteiras da Técnica. Rio de Janeiro: Agir Editora, 1952.

FIORI, N. A. Aspectos da Evolução do Ensino Público: ensino público e política de assimilação cultural em Santa Catarina nos períodos Imperial e Republicano. Florianópolis: Editora da UFSC e Secretaria da Educação do Estado de SC, 1991.

GIDDENS, A. As Consequências da Modernidade. São Paulo: Ed. Unesp, 1991.

HUGHES, T. P. Networks of Power. Eletrification in Western Society, 1880-1930. Baltimore: The John Hopkins University Press, 1983.

LATOUR, B. Aramis or the Love of Technology.

Cambridge, Mass., Harvard University Press, 1996. 
LIBÂNEO, J. C.; PIMENTA, S. G. Formação de profissionais da educação: visão crítica e perspectiva de mudança. Educ. Soc., v.20, n.68, p.239-277, 1999. Disponível em: $<$ http://www.scielo.br/scielo>. Acesso em 26/03/07.

LIMA, L. de O. Mutações em educação segundo Mc Luhan. Petrópolis: Vozes, 1971.

MENDONÇA, A. W. Anísio Teixeira e a Universidade da Educação. Rio de Janeiro: EdUERJ, 2002.

NASCIMENTO, A. B. A capacitação digital de estudantes de Licenciatura em Geografia na UFSC. In: XVI Seminário de Iniciação Científica da UFSC, 2006, Florianópolis. Anais do XVI Seminário de Iniciação Científica. Florianópolis: CNPq, 2006. 1 CD-ROM, 2006.

OLIVEIRA, G. P. de. Fluência tecnológica, comportamento e complexidades: um laboratório de informática, o tempo, as pessoas e outras coisas. Ensaio: Avaliação e Políticas Públicas em Educação, v.13, n.48, p. 307-332, 2005. Disponível em: <http://www.scielo.br/scielo>. Acesso em 26/03/07.

OLIVEIRA, R. de. Informática educativa. Campinas: Papirus, 1997.

PEREIRA, W. C. (org.). Educação de professores na era da globalização. Subsídios para uma proposta humanista. Rio de Janeiro: Ed. Nau, 2000. 
SALAZAR, R. O Programa Nacional de Informática na Educação (ProInfo) em Santa Catarina: uma análise sociotécnica das capacitações (2002-2004). Dissertação de Mestrado. Florianópolis: PPGSP/UFSC, 2005.

TOFFLER, A. A terceira onda. Rio de Janeiro: Record, 1980.

VARGAS, M. Para uma filosofia da tecnologia. São Paulo: Alfa-Ômega, 1994. 
